\title{
Personal Values and the Value of Expert Testimony
}

\author{
Robert G. Pachella*
}

Psychologists who routinely offer expert testimony to the cours about the problems of eyewitness testimony demonstrate an unwarranted degree of faith in experimental psychology. Although progress in the field ultimately depends on laboratory research, the extrapolation of laboratory research to the real world is fraught with difficulties. Among the difficulties are the following: Laboratory studies are typically not designed with ecological validity in mind, they involve "fixed effects" statistical designs, they do not tell us how individuals (as opposed to mean values) behave under various experimental conditions. Presentation of such studies as relevant to the specific conditions of a court case entails a significant misrepresentation of the results of the research.

The topic of Professor Buckhout's paper is "personal values and expert testimony." Any number of personal values could be brought up under such a topic, some of which are discussed by Buckhout, many of which are not. Each of us holds certain idiosyncratic values that in one way or another might affect the types of cases that we might get involved in or the kind of advice that we might be willing to give to a jury. Clearly these values and biases need to be examined and understood if we are to make reasonable ethical judgments about our roles as experts in the courtroom. However, there is one personal value that Professor Buckhout does not discuss explicitly, indeed, that is not discussed in any of the papers in this issue, but that implicitly underlies all of the other values that have been discussed. Further, explicit or implicit, this value necessarily underlies the testimony of an "expert," if only to meet the legal requirement of being admitted

\footnotetext{
* University of Michigan.
} 
to a court as an expert. And while Professor Buckhout does not mention this value, his paper virtually reeks with it. ${ }^{1}$

The value to which I refer is that of unabashed, unmitigated faith in the quality of what experimental psychology has to offer to the legal system. Professor Buckhout really believes in experimental psychology. He believes in its methods and its findings. And as far as I can tell he believes in them with hardly any reservation or limitation. He has the confidence to go into a court of law and generalize the findings of laboratory studies reported in technical journals to the kinds of situations that arise in court cases. He is willing to apply theoretical models presented in scholarly monographs to the complexities of the real world, and he is willing to do so where the lives and freedom of real people hang in the balance. In short, he promotes an advocacy model of the expert, where the advocacy is not for one side or the other of a particular legal case, but the advocacy of experimental psychology itself.

I will argue in these brief comments that such faith is unwarranted. I fundamentally disagree with him about the quality of the methods, findings, analyses, and results of experimental psychology. I do not believe in experimental psychology in the way that Professor Buckhout does. Further, I do not think that Buckhout's point of view is representative of the psychologists in the field who actually conduct the research on which Buckhout bases much of his testimony. That is, I believe that many of them would be much less confident about bringing their own research into courts of law. I will argue that to many experimental psychologists a willingness to testify on matters of experimental psychology, with a willingness to generalize its findings to court cases, demonstrates a fundamental lack of understanding of the field itself.

Now such disagreements between academicians are hardly the occasions for much note away from our ivory towers, and in this case the disagreement seems truly to be a matter of opinion. But in the present circumstance the debate is hardly academic. What we are questioning is whether, as a matter of law, any experimental psychologist can qualify as an expert, given the nature and level of belief that the practitioners of the field have in their own findings. ${ }^{2}$ And on this point, psychologists who serve as expert witnesses hardly qualify as a representative sample. The feelings of a much broader contingent of experimental psychologists about this question are of profound importance to both psychology and the law, and undoubtedly should be assessed.

To begin with, one might ask how I can call myself an experimental psychologist and not "believe" in it. Is not my position inconsistent or, at the very least, terribly cynical? No, I do not think it is. I think psychology is an extremely important and interesting field of study. I also have great respect for my colleagues: the field is full of very smart people who work hard at what they do. Further-

\footnotetext{
${ }^{1}$ If is is not otherwise obvious from its tone, it should be noted that this paper represents a subjective, personal reaction specifically to Professor Buckhout's papers. To the extent that the values discussed reflect the values of others, the present comments can be generalized accordingly.

2 Note the comments in this issue by Konecni and Ebbesen (1986) regarding the legal requirements defining expert testimony under United States $v$. Amaral and Frye v. United States.
} 
more, I am convinced that progress in the field will ultimately depend on laboratory studies. Nevertheless, as anyone who has participated in the editorial process in one capacity or another can tell you, it is a surprisingly easy exercise to find fundamental flaws in the design, logic, statistical analysis, or theoretical leap in virtually every experimental study that we see, including our own. This judgement does not represent a condemnation of the field, rather, it is simply a commentary on how hard it is to do experimental psychological studies. Thus, relative to the criterion of taking our product into courts of law, I just do not think that what we have produced in our laboratories, up to this time, is very good. Our progress to date, to the extent that we have marked it at all, has mostly been to eliminate a number of methodological blind alleys, which is an important scientific achievement, albeit of a negative variety. But it does not substitute for having positive answers for the kind of applied questions that are raised in court.

One may then ask: Why continue to do experiments at all? And why publish studies that have flaws in them? The answer is simply that we do the best we can. Clearly no progress of any kind would be possible if we did nothing at all. As for publishing, it performs a critical communicative function. We owe it to each other as researchers to inform the scientific community of what we have tried and what resulted, even if it may not be very good in some absolute sense. And it is important with regard to legal questions to understand this: Publication represents only the best of what we produce. It does not certify the results as "truth" or even as "facts" that are to be "believed" in. Publication in scholarly journals is not the sole criterion for the acceptability of, or belief in, findings. If as professional psychologists we do not fully appreciate this fact, we should not compound our naivete by passing it on to the legal profession.

What are my biggest misgivings about taking experimental studies into court? The most obvious problems are those of relevance. This topic is discussed in this issue under several guises, but two are worth reiterating: the lack of generalizability and the misrepresentation of results. ${ }^{3}$ Laboratory studies are typically not designed with ecological validity in mind, they are usually intended to test some borderline prediction of a relatively (at least relative to the real world) esoteric theory. The stimuli, subjects, and tasks are not representative of circumstances that arise in the real world. Nor are they intended to be. In statistical terms, they involve "fixed effects" logic. They are designed to determine if certain specific results can be reliably obtained under special and often highly contrived conditions. They are not designed to estimate particular population parameters from appropriately derived population samples. In the vast majority of cases, the original researcher is engaged in an hypothesis-testing mode of inference, in which the finding of a particular result is intended to be a counterexample, a demonstration of how some particular theory cannot hold. In these cases investigators do not intend their results to be generalized; in fact, they do

\footnotetext{
${ }^{3}$ It should be noted that the observations raised in this and the following paragraph are not intended to raise the general and obvious issue about the tentative nature of all "state of the art" scientific research. Rather, the intent here is to note that the specific generalizations presented are not allowed by the fixed effects experimental designs employed in the typical studies under consideration.
} 
not even bother to compute estimates of the relevant population parameters. Accordingly, the presentation of such studies as relevant to the specific conditions of a court case, to people who are not trained to deal with these limitations (i.e., judges and juries), entails a significant misrepresentation of the results of the research.

Similarly, court cases usually ask questions about the abilities of individual witnesses. But our experiments are rarely designed to estimate the performance parameters of individual subjects. Our statistical inferences are based on mean values, from averaging over groups of individuals. A completely different kind of experiment needs to be carried out in order to answer questions about how individuals, as opposed to mean values, behave under various experimental conditions. As noted above, mean values are useful for testing esoteric methodological or theoretical questions, or for eliminating blind alleys. But the offering of mean values, under these circumstances, as representative of the performance of individuals in real world settings is nothing less than a misrepresentation of facts.

Consider for a moment the example of cross-racial identification, a topic that has been reviewed by Loftus (1979) with regard to legal issues and that is discussed in several papers in this issue. Assume hypothetically that the question before a jury hinges upon the identification of a white assailant by a black victim. And assume further (and this may be quite an assumption, probably placing our example truly in the realm of the hypothetical) that there exists a body of laboratory studies that demonstrate unequivocally that subjects, on the average, identify people of their own race "better than" people of a different race. With regard to relevance, we are first confronted with a logical problem. Not only do our results not address themselves to the particular witness in the case, but "better than' is a purely relative term. Such studies do not tell us whether facial identification, regardless of racial considerations, is good, bad or indifferent. Now, the relative performance of cross-racial versus within-racial groups may be of interest to certain researchers for purely theoretical reasons, but should this be all a jury should be told? Putting aside the question of race, there is a literature that could be cited to support the hypothesis that facial identification is extremely good (e.g., Clarke, 1934; Bahrick, Bahrick, and Wittlinger, 1975; Davies, 1978). What jurors need to be told are the relevant population parameters of performance, not the relative performance of subjects in laboratory experiments.

Furthermore, let us assume that the relative inferiority of cross-racial identification represents a true fact of nature. The relevant question is how big is the difference? The statistical fact is that, if a difference is real, regardless of its size or importance, studies can be designed for laboratory purposes that will achieve statistical significance. Again, the relevant question for a jury is what is the actual size of the difference in the general population? However, this question cannot be addressed unless the materials, subjects, and conditions of the experiment were constructed to sample the relevant population and real world circumstances. And few, if any, of our experiments do that.

Now, let us assume even further that real differences could be found and that they were large. For example, imagine that we had found for some reasonably defined population that $60 \%$ of the subjects tested in our experiments were worse 
at identifying people of other races than people of their own race. Ought we really tell a jury that cross-racial identification is inferior? We are presented here with an equally significant statistical fact $-40 \%$ of the subjects were actually better at identifying people of other races! The questions most relevant to the jury in our hypothetical case are, what are the factors that discriminate these two subpopulations, and to which of these does our particular witness belong? This would require that we could reliably examine our particular witness with regard to these factors. But, of course, as nonexamining experts we are not in a position to do this. Our present studies are typically not designed with these questions in mind; and these parameters cannot even be extrapolated from the existing data, since the studies have not used samples and conditions representative of the real world.

Thus, it seems to me that to go before a jury as a nonexamining expert, and to present irrelevant and inaccurate generalities as if they were the critical information that a jury needs in order to determine the veridicality of a particular witness, constitutes a serious misrepresentation of the status of experimental psychology. It is at best confusing, and at worst highly prejudicial. And, keep in mind that cross-racial identification is just an example: The arguments presented here could have been constructed about the generalization of virtually any of the "facts" that we have obtained in psychological laboratories. ${ }^{4}$ While we certainly have things that we can tell to juries, and perhaps we could even call these things the "state of the art," they are simply not the things that juries need to know.

Is Professor Buckhout's belief in the generalizability of experimental psychology representative? This is a difficult question to assess and certainly, at this time, strictly a matter of opinion. But $I$ do not believe it is, and the basis of my opinion is, very simply, the reaction that I have observed of our non-legal-consulting colleagues when the question arises. Many of our colleagues are not particularly aware of the increased frequency with which experimental psychologists have become engaged with these legal questions. On occasions when I have brought to their attention just the fact of this involvement, without even raising the question of its appropriateness, I have often found their reaction to be one of genuine surprise, if not outright incredulity. When this happens, I often find myself in the position of defending the thesis that there is a contribution in this area to be made by our profession, which, in spite of the tone of the present comments, I genuinely believe. Of more importance, when I find myself defending this position, I find that my colleagues' arguments are remarkably similar to those of the prosecutors and judges who argue against our inclusion in a trial. Namely, that our testimony represents an invasion of the province of the jury, that at this level the best we have to offer is nothing more than the knowledge that a layman can derive on the basis of common experience. And the most persuasive argument that they present, which I think is the critical test of the relevance of the facts that we might want to present in court, in this: For all of their knowledge of the facts of experimental psychology, my colleagues do not feel that this knowledge would make them better jurors at determining which witness or whose testi-

\footnotetext{
${ }^{4}$ See Loftus (1979), Chapter 3 for examples such as "weapon focus" or the impact of stress.
} 
mony to believe. In other words, they do not believe that in the specific circumstances that arise in the kind of trials we are asked to comment on, hypothetical juries made up out of experimental psychologists would be more likely than those made up of laymen to arrive at veridical decisions.

Finally, we come to the question of the relationship between ethics and professional responsibility. Certainly, the scientific journals and literature belong, in some sense of the words, to the public domain, and once a paper is published, a researcher loses control over its uses. Nevertheless, a researcher can find it deeply disturbing to see his or her work misrepresented, distorted, presented out of context and/or used for purposes for which it was not intended. In such instances, it seems to me that an implicit, yet important, social contract has been violated. If a significant proportion of the members of the professional community experience a sense of violation, then the activity should either be stopped or at least widely denounced to the general public.

\section{REFERENCES}

Bahrick, H. P. Bahrick, P. O., \& Wittlinger, R. P. (1975). Fifty years of memory for names and faces: A cross-sectional approach. Journal of Experimental Psychology: General, 104, 54-75.

Clarke, H. M. (1934). Recall and recognition for faces and names. Journal of Applied Psychology, 18, $757-763$.

Davies, G. M. (1978). Face recognition: Issues and theories. In M. M. Gruneberg, P. E. Morris, and R. N. Sykes (Eds.), Practical aspects of memory. New York: Academic Press.

Frye v. United States, 293 F. 1013 (D.C. Cir. 1923).

Konečni, V., and Ebbesen, E. (1986). Courtroom testimony by psychologists on eyewitness identification issues: Critical notes and reflections. Law and Human Behavior, 10, 117-126.

Loftus, E. (1979). Eyewitness identification. Cambridge, Massachusetts: Harvard University Press.

United States v. Amaral, 488 F.2d 1148 (9th Cir. 1973). 